\title{
HEGEL ON PROVING THE EXISTENCE OF GOD
}

In $\$ 36$ of the Science of Logic in his Encyclopedia of the Philosophical Sciences Hegel presents some reflection on the historical attempts at proving God's existence and properties. Complaining about what "rational theology," operating on "understanding" (Verstand) instead of "reason" (Vernunft), has been able to accomplish in conceptualizing the object of its inquiry, Hegel develops this argument in some comments of the Zusatz on the traditional existence proofs:

Now, in this matter, the main point to be noted is that demonstration, as the understanding employs it, means the dependence of one truth on another. In such proofs we have a presuppositionsomething firm and fast, from which something else follows; we exhibit the dependence of some truth from an assumed startingpoint. Hence, if this mode of demonstration is applied to the existence of God, it can only mean that the being of God is to depend on other terms, which will then constitute the ground of his being. It is at once evident that this will lead to some mistake: for God must be simply and solely the ground of everything, and in so far not dependent upon anything else. And a perception of this danger has in modern times led some to say that God's existence is not capable of proof, but must be immediately or intuitively apprehended. ${ }^{1}$

Though containing familiar elements in its orientation to the traditional proofs and the traditional concept of God, the aim of this argument is unusual in the history of rational theology. In the still more recent modern times of the next century, unprovability has of course also led some to say that God's existence must be immediately

1 Hegel's Logic, trans. William Wallace (Oxford: Clarendon Press, 1975, p. 58. Corresponding references in the original are made to the Wissenschaft der Logik of the Enzyklopädie der Philosophischen Wissenschaften im Grundrisse (Vol. 8 in Hegel's Werke, Surkamp Verlag, Frankfurt am Main, 1970), cf. p. 105. Page numbers to these sources are hereafter designated ' $\mathrm{HL}$ ' and ' $\mathrm{WL}$ ' respectively. 
rejected; however, neither reaction seems to have much to do with the "danger" that Hegel envisions here, or the particular theoretical impossibility that he sees obstructing the attempt ever to devise such arguments. Hegel's argument, itself a demonstration of sorts for establishing a conclusion about (how to establish conclusions about) God, goes beyond the standard Humean criticism of contingent demonstration tailored more closely to exhibits of evidence and principles of inference contained in specific versions. In an attack, rather, on a pervasive mistake endemic to a "mode" of theological argumentation, Hegel's criticism may indeed seem to go so far beyond as to make it difficult to see exactly how the point being argued relates to any specific historical attempts at all. On the other hand, while Hegel's more global refutation out-Humes Hume as a wholesale elimination of a broad range of theistic arguments, its ambition is more modest than any of the classical indictments that rational theology has handed down against God's existence itself. While an a priori demonstration of sorts, Hegel's proposal is not an "ontological" disproof of the existence of God; Hegel in fact accepts, we will see, the ontological proof for the existence of God, and appears to subscribe to some empirical argumentation as well. Hegel's ontological disproof of a method of demonstration purports a wholesale elimination of a broad program of proofs affirming God's existence in the wrong way, and thus may seem to offer at a more fundamental level an account of why the more limited kind of criticism against the traditional proofs should ultimately win, or at least the arguments themselves lose.

Hegel's argument in this passage does not at any rate seem very convincing. At face value the argument appears to assert a relation of two definitions and a modus-tollens deduction out of that relation. In schematic form this argument would run as follows:

1. By definition of what a contingent demonstration of the understanding is, if there were to be any successful demonstration for the existence of God, then the truth of the conclusion (in this instance that God exists) would have to depend on the truth of the premises (whatever they may be in any and all such theistic applications).

[I.e., because generally in any contingent demonstration of the understanding, the truth of the conclusion must depend upon the truth of the premises used to derive it-whenever it does not, there just is not really any logical derivation going on, and thus 
the argument is simply invalid and does not really demonstrate anything.]

2. But by definition, it is not the case that God's existence could so depend on the truth of any other contingent premise-set about the world.

[I.e., just the other way around: God is precisely the being upon which everything else, which could possibly be packed into the premise-set of any such contingent argument from facts of the world, is supposed to depend; thus when God is made to be a conclusion there could be no premises available from which to derive it, and so the consequent of (1) is false.]

3. Therefore, by definition it is not the case that there is any possible contingent demonstration of the understanding that succeeds in proving the existence of God.

[I.e., the antecedent of (1) must also be false-from (1) and (2) by modus tollens.]

There appears to be an obvious equivocation here on the notion of 'dependence'. Admittedly, it is true in one sense of the term that to have an argument "means the dependence of one truth upon another," but it does not seem that the indepenedence of the existence of God as "simply and solely the ground of everything," must be incompatible with this sense of 'dependence' required merely by the format of any argument having premises and a conclusion. In general, which is how Hegel appears to be arguing it, logical dependency of premises and conclusion has very little to do with "grounds for being" (der Grund vom Sein) or what, as this expression would suggest, might be considered an 'existential dependency' of some sort. Premises can logically imply all sorts of results as conclusions of deductively valid arguments without this meaning anything about the dependent relationships of existence that the things involved may bear to each other, how they came into being or are maintained, or anything of the kind. Retrodictions into the distant past of the constellations of celestial bodies can, from their present positions and the general principles of motion, gravitation, etc., that have prevailed since then, be expressed as the conclusions of valid deductive arguments; no one would contend, however, that this makes the position of a planet two thousand years 
ago depend, in any sense relevant to its "being" where or what it was then, upon where it is now or upon physical laws subsequently in effect. If this were not obvious, one could, of course, just as easily turn the argument around and deduce a planet's present orbit in the same way as dependent upon the same laws and a past position. While it may be perhaps somewhat more plausible in this case that some such extra-logical dependency as required above might hold. (i) both of these arguments are equally valid; (ii) it would be arbitrary, then, as concerns the underlying "mode of proof" to attach any such special significance to the argument when it is going one way while not when the same kind ("mode") of argument is going the other; (iii) and yet surely two things do not mutually at the same time so depend upon each other's existence.

Mere logical dependence, obtaining among propositions in proofs for deriving logical results, seems-as a matter of general observation about the process of "demonstrating" conclusions, and to the contrary of what Hegel seems to be arguing above-something quite different from any deeper perplexity concerning dependency of 'being'. When in propping up premise (2) Hegel demands that God be "simply and solely the ground of everything and in so far not dependent upon anything else" (der Grund vom Allem und hiermit nicht abhängig von Anderem), the problem is how this sense of "dependency" (Abhängigkeit) is supposed to get in the way of the sense in premise (1) by which demonstrations characteristically derive their conclusions, as in the illustration of physical laws: In premise (1) it is not, after all, really the truth of the conclusion which depends upon that of the premise (s) in the sense that the latter somehow, out in the real world of being and not merely as a logical relation inside of the argument, determines what that truth is to be-or preserves it, provides any causal nexus for explaining it, etc., for whatever else may be subsumed under the rubric of regarding one thing as the "ground" of another thing's being the way it is. This does not follow as any part of the condition in the generalized bracketed reasoning behind the first premise, stipulating minimally only what is needed to get a logically sound proof, and where such extra-logical entailments may be running in even the reverse relationship to that "demonstrated" in the logical proof.

The trick is sticking together these two distinct senses of dependency, and the glue which Hegel's argument appears implicitly to 
rely on here is neither logic nor being, but rather a psychological aspect of contingent demonstrations in their capacity to impart new facts to those who contemplate them. The transition occurs above in the line, "...it can only mean [i] that the being of God is to depend on other terms, [ii] which will then constitute the ground of its being" (this identification stands out in the twin grammatical constructions of the original: "...so erhält dies den Sinn, [i'] daß das Sein Gottes von anderen Bestimmungen abhängen soll, [ii'] daß diese also den Grund vom Sein Gottes ausmachen"). But the only way to get the appropriate meaning of "depending on" (abhängen von), thereby making good the "then" (the German 'also') inference, is to assume more than what we've seen above one is entitled to assume merely to get a logical demonstration that proves a conclusion from premises presupposed (the Vorausgesetztes) for the sake of demonstration-otherwise the transition from (i) or (i') to (ii) and (ii') doesn't come off. The only "extra-logical" relationship that this seems to involve, however, is again not one in which a (demonstrated) truth is depending upon another (presupposed) one, i.e., somehow in order to be the truth at all as a metaphysical fact; rather, in such demonstrations it is only the subjective recognition of such truths as depending upon the recognition of others, i.e., as an epistemic fact, that is taking place. Thus it is in the above illustration where the truth of scientific laws and present astronomical data is not metaphysically responsible for any past events being what they are, but when exhibited in a persuasive demonstration can be epistemically responsible for their recognition as such. This equivocation is the backbone of Hegel's argument: Either the truth of premise (2), where the notion of 'dependency' has to be construed in the metaphysical sense in order to make this premise true, is a non sequitur compatible with the consequent of (1) and rendering the argument invalid; or the notion of 'dependency' in (1), in order to bring it in tune with the sense of (2), is hereby stripped of any support it could receive in its merely logical or psychological senses, rendering this premise false, and the argument so construed, if logically valid, nevertheless unsound.

There may seem to be two loose ends to this criticism of Hegelone concerning the notion of the 'ground of being' characterizing God's relation to the world, and the other concerning the notion of

theistic argument that he is rejecting as incapable of dealing with this 
correctly. First, while the notion of 'dependence' for deductive demonstrations is clear, no attempt has been made to clarify more exactly what the special sense of 'dependence' is in which the world 'depends' on God. Indeed, it has been suggested only that this meaning, whatever it is, is at any rate distinct from the sense pertaining to deductive demonstrations, thus not precluding from the outset, as Hegel seems to argue it does, a successful one for God's existence. Some may find it unconvincing that this result could be established, a result about the relation of two things, until both of the two things have been adequately characterized, but especially in the case of the above argument, as one may be ("intuitively") inclined to counterargue that the dependence of the world on God is quite different from any contingent dependencies connecting objects in the world such as those involved in the laws of physics and planetary motion.

On examination, however, this does not appear very damaging to the criticism. The proper reply, it seems, merely to meet Hegel's argument, does not have to contest this alleged discrepancy, nor, as would be needed in arguing it one way or the other, to delve in more precise terms into the concept of God and his special relation to the world vis-à-vis the mundane causality of material bodies. Causality provides an everyday garden variety of 'dependence' among objects in the world, and people argue down through the history of philosophy, in an explicitly theological context as well as in philosophy of mind, about how God is supposed to be regarded as "causing" the world itself to generate the special 'dependence'. Taking off from the familiar paradigm, this idea begins by "treating the world as a great big object," itself along with all of the objects it comprises (planets, or pool balls, as Hume preferred to discuss this topic), dependent on causative agency. ${ }^{2}$ Thus, for instance, one gets the creative cause in Christian theology, or, in greater philosophical dress, the "clockwinder" agency in Leibniz's theory of "pre-established harmony." Some of Descartes' argumentation in the Third Meditation seems to implicate God as both an initiating and sustaining, preservative "cause" of the world; while Spinoza's theory of God's "occasional" intervention can be viewed as breaking down the latter theory of continuous causal agency to more specific kinds of events. Or in a similar way,

2 See P.T. Geach's discussion of Aquinas in Geach and Anscombe, Three Philosophers (Oxford: Basil Blackwell, 1961), pp.112ff. 
Descartes' postulate of God as the cause of a certain idea could be seen to particularize Berkeley's theory of God as the cause of all ideas. Of course, some of this cosmic "cause-and-effect" application tends to deviate quite a bit from the normal sense of this notion-to be expected since the world is not a normal effect and God is not a normal cause: The usual temporal element, for instance, i.e., that causes precede their effects in time, seems to drop out, as developed in more recent commentary on Aquinas and the "first cause" of infinite regress arguments even traditionally conceived. ${ }^{3}$

But now none of the potential options of this sort of discussion seems to have any crucial impact which would rehabilitate Hegel's equivocation concerning the 'dependence' of the world on God and a conclusion about the mistake of traditional theistic arguments. None of these souped-up interpretations of causation to accomodate God/ world dependence seems to have anything more to do with logical dependence in arguments, than does the case of normal "objects," planets and pool balls, etc. Calling attention to differences between these cases does not appear to help Hegel, since (i) the similarity common to all of them is at any rate that each seems to give an account of why facts about the world are what they are, or how they come to be what they are, and it is this common element that arguments accounting only for logical relationships between facts, however produced, perpetuated, etc., do not seem to bring into question. On the other hand (ii), making an issue of dissimilarity here, dragging in as it does a special kind of dependence much more problematic and about which everyday intuitions are much more vague, would seem only to make it more difficult for Hegel to argue with clarity a general principle underwriting the contrary claim implicit in his above comments. This difficulty would also impede the project of showing such a connection between logical entailment and any more recent interpretations from modern theologians on what in these remarks is termed "ground of being." Hegel, at least, does not attempt to show anything of this nature, nor finally, any of the above connections either-rather, we've seen that Hegel does not appear to notice a distinction requiring a connection of one kind of dependence to another. The argument appears simply to gloss over the distinction from the dependence of the world on God to a conclusion about the success of

"Patterson Brown, "Infinite Causal Regresșion," Phil. Review (1966). 
the tradition of theological argumentation. The illustration of temporal causality is intended merely to delineate this general distinction, but to do this it does not seem necessary to explore in any further detail the various processes of determination, including any of God's alleged roles in this, that could conceivably be, or have historically been, proposed. The intent of the criticism against Hegel's argument should be satisfied if it can, on a level no more detailed than that on which Hegel's own argument operates, show a distinction in the senses of 'dependence', and show that generally, in the case where intuitions are relatively clear, one cannot shift automatically from one to the other as Hegel seems to do. Of course, whether one can or cannot, at least when one does this should be announced.

It may be felt that the foregoing criticism, having neglected then the second main aspect of Hegel's argument in its focus on demonstrations of understanding, is a hopeless straw-man construal missing entirely Hegel's point in the broader context of his philosophical system. The immediate context of Hegel's above remarks in $\$ 36$ poses a dichotomy between the mode of demonstration by understanding, and another mode, the mode of reason. Hegel is much happier with this mode, and perhaps in assessing the two modes what is right with the latter, following as it does in the same paragraph, may be taken as a key to what is supposed to be wrong with the former. Dismissing the earlier suggestion that, with the failure of understanding, God's existence is undemonstrable (nicht zu beweisen), i.e., by any mode, Hegel says:

Reason, however, and even sound common sense give demonstration a meaning quite different from that of the understanding. The demonstration of reason no doubt starts from something which is not God. But, as it advances, it does not leave the starting-point a mere unexplained fact [als ein Unmittelbares und Seiendes], which is what it was. On the contrary it exhibits that point as derivative and called into being, and then God is seen to be primary, truly immediate, and self-subsisting, with the means of derivation wrapped up and absorbed in himself [Gott als der die Vermittlung in sich aufgehoben Enthaltende, wahrhaft Unmittelbare, Ursprïngliche und auf sich Beruhende]. ${ }^{4}$

4 HL p. 58; WL pp. 105f. Wallace's rendering of Hegel's "indem... so ergibt sich zugleich" construction by "and then " may seem somewhat pale here in the last sentence of English text. Actually, on this particular occasion at least, 
It is not clear what the proposed distinction here is; it does not seem to be raising a question of whether God's existence is provable, but it is not clear that what is in question could be characterized in a way that would promote Hegel's criticism of proofs from 'understanding', or make any further tie-in between the theological arguments and his philosophy more generally. If the idea of proving God as "primary, truly immediate..." and so on, is what fundamentally distinguishes arguments of 'reason' from arguments of 'understanding', surely people in the history of "rational theology" who have argued the standard proofs for the existence of God have conceived of God in this way, and it is puzzling, then, what there could be about the proofs themselves, all motivated accordingly, that would differentiate them into Hegel's modes. The positive point here does not seem to carry out Hegel's preceding criticism, since the logical dependence of deductive conclusions on premises yielding them would presumably be a problem whether the argument conceives of God in this way or not. It is hard to see what contextual refinement could be performed on this criticism to salvage any observation that Hegel would want to make attaching significance to, or finding any "mistake" or "danger" in, the mere dependence of one truth on another in valid demonstrations-this dependence should itself be independent of the primacy of God, as for any other (meta) physical facts of the world, even if some theistic proofs, but not others, were shown somehow to compromise this.

As an example of a classical argument from reason which Hegel believes does not-which presumably handles God's primacy, immediacy, self-subsistance, etc., in the appropriate way-Hegel goes on in the above passage to submit this:

Those who say: "Consider Nature, and Nature will lead you to God; you will find an absolute final cause" do not mean that God is something derivative: they mean that it is we who proceed to God himself from another; and in this way God, though the consequence, is also the ground of the initial step.

Hegel's notorious proclivity for marathon syntax seems to go more smoothly than the edited dissection-which, under the auspices of translation in Hegel scholarship generally, can, it seems, also get out of hand at times in the opposite direction. 
The idea of "final cause" here is not, as the conventional English expression might intuitively suggest, the terminal "cause" which one reaches (through "reason") going back in a sequence of causes, i.e., until "finally" reaching a first cause. This literal ambiguity is absent in the German Endzweck, i.e., (final) "design" or "purpose," indicating that it is the so-called "teleological" argument, and presumably not other "cosmological" forms, that Hegel means to be talking about." The direction of finality is that to which rather than from which causes proceed, i.e., to some higher kind of "cause" (or Z weck) essentially unlike other (contingent) causes and which may seem in this sense more like an "effect"; Hegel wants to consider the peculiar God/world sense whereby all "causes" of the world are derivative of their overall "effect": the designed, purposive orientation toward which things proceed and in terms of which they are to be explained in a rational pattern.

It is not clear what this example is supposed to exemplify, or again, how Hegel's above distinction is to apply selectively in view of other historical attempts to prove the existence of God. The 'reason'/'understanding' distinction does not appear to be selecting out any idiosyncrasy of teleological thought or anything particularly meritorious that is not inherent in contingent demonstrations generally. Certainly in any of the popular contingent arguments, even in any other cosmological forms, the necessity, or "absoluteness," of the conclusion will serve to exhibit the contingency of whatever facts of the world are reported in the premises, which facts are seen, then, as "derivative" or "dependent" for their being upon God. Even in a standard causal regress argument the conclusion will presumably have this relationship to the premises and will provide an "explanation" for the contingent starting-point. This seems to be just the normal way in which Church Fathers like Aquinas argued for God in general. Certainly nobody in the history of "rational theology" which Hegel is addressing ever "means that God is something derivative" in this sense, but if not, then who is Hegel arguing against here? The conclusion that

${ }^{5}$ Hegel keeps this labelling separate in his kosmologisch/physikotheologisch distinction at WL p. 130-designating "the Cosmological proof" and "the proofs of Natural Theology" in the translation at HL p. 80. (Hegel refers to both in the singular, i.e., as general forms of argumentation, though there are, of course, lots of variants of each.) The arguments are not always "so-called" (WL p. 131): Sometimes 'cosmological' is used widely to include 'teleological': cf. John Hick, ed., The Existence of God (New York: The Macmillan Company, 1964), p. 71 . 
the traditional God exists, in an argument that "started from something which is not God" but then ends up with God-whether the "prime mover" or (first) cause of the world, the "necessity" underlying all "contingency" in nontemporal regress, or the telos of the universe, etc.-could never, as Hegel puts it, "leave the starting-point a mere unexplained fact." It must, rather, always be "the ground of the initial step," which position perforce confers its status as the wrapped up and absorbed," etc. (otherwise regresses would go on regressing) final step. Thus, if the teleological argument exemplifies the mode of demonstration from 'reason', what standard theological arguments are there which do not? The answer cannot be that the other main contingent arguments do, but that Hegel just doesn't consider any of them logically sound, since there would still remain the problem of pinning down Hegel's opposition and making sense of his entire commentary on 'reason' and 'understanding'; indeed, while this would simply be the traditional criticism, Hegel's criticism (of 'understanding') has seemed to make validity even a handicap for good theological argumentation. This problem is perhaps more conspicuous in translation where Hegel commends argumentation that does not (criticizes argumentation that does) "leave the starting-point a mere unexplained fact, which is what it was." in the structure of the German text, conveniently prompts curiosity in the relevance of Hegel's remarks to rational theology: Where or when "was" it ever supposed to have been this way-who are the theologians of 'understanding'? The inventory of historical endeavors to demonstrate God, but doing so through the inadequate mode and thus presumably deserving of Hegel's critique in $\$ 36$, would seem very limited, in fact to be vacuous.

Hegel's observation on the "final cause" argument seems to concede the very distinction between (psycho) logical and existential dependencies which the criticism of 'understanding' confused. Though Hegel has shifted from the expression "dependent" to "derivative"

" N. 4 supra. It is not clear whether the past tense "was" here is to be taken from a standpoint referring to the state of the premises before 'reason" explained them, or after 'understanding' failed: i.e., whether Wallace intends this redundancy as emphasis for the progress ("does not leave...what...was") that reason accomplishes on its, initially unexplained, starting-point, or whether it is meant to facilitate Hegel's contrast between what "was" (unexplained) in (even the end-point of) the mode of understanding but is (now) rectified in the mode of reason. Of course, either sense of the nuance fits Hegel's message, and neither in Wallace purports actual rather than an expository past, though this is the main problem that Hegel's own exposition seems to leave. 
(abhängen/vermitteln) and though he is supposed to be characterizing demonstrations of reason, his discussion is acknowledging a kind of dependency or "derivative" relationship that obtains in the course of arguments (of reason) and consists merely in the fact that "it is we who proceed to..." the conclusion (God) from certain premises ("from another" state of affairs which is not the conclusion). This is distinguished from the dependency of being that relates (meta)physical facts of the world and pertains more fundamentally to the determination of why (i.e., the question here of "explanation") they are the facts of the world. The former, as noted above, is a spin-off of logical dependency in demonstrations which demonstrate things to individuals who are benefiting epistemically from them; they function as instruments of discovery by which we proceed, and perhaps not how nature proceeds, to establish the facts inferred in the conclusion from those narrated in the premises. This is a purely subjective sense of what, in the context of logical argumentation, the notion of dependency can mean-the personal pronoun "we" (wir) receiving italics in the original (though not in Wallace), thus indicating Hegel's intent to stress this. ${ }^{7}$ But if, as Hegel asserts for demonstrations of reason, logical derivation does not run any interference to the sense in which nature is "derivative" of God, why should it be so regarded in the ap-

7 Of course, the idea of "explanation" may seem also quite "subjective," i.e., as characteristic of the process of mind by which we sentient perceivers read purposes or designs, or Hegel's Endzwecke, into the processes of nature. However, Hegel's reference to God as "calling into being" the contingent facts of the world (the Vermitteltes und Gesetztes) seems to associate more closely the notion of teleology and purposive 'explanation' with natural processes, as just another "objective" aspect of their "being." Though it is a practical drawback of arguing from teleological explanations that the purposes of natural events are explained in terms of, and would appear rather to be indicative of, the purposes of humans, and are thus prone to vary with subjective assessments (vis-à-vis proverbial strange ones, like: rabbits have white tails for the purpose of making them easier to shoot; faces are equipped with noses in order to hold glasses in place; and so on), Hegel's appeal to the standard notion of "absolute cause," i.e., absoluter Endzweck (WL p. 106), dismisses any "subjective" or relativistic implication that may seem to attend the notion of 'purpose' itself, relative to any aspirations, including those of a being conceded to be "absolute." With the dismissal, too, of any of the standard logistical problems of catering this argument to human aspirations (the problem-of-evil suggestion to turn the teleological argument inside out, the availability of "naturalistic" or evolutionary explanation for what remaining human-oriented telos there appears to be, etc.), presumably on this view the disclosure of conflicting purposes of even, say, a deceased or retired clock-winder God would settle, even for beings with other purposes, what the unique (absolute) 'purpose of nature' is for them, as an "objective," metaphysical (not merely eschatological) statement about the events of nature themselves. 
plication to understanding? The response to the argument in (1)-(3), consistent with Hegel's own admissions here, might be paraphrased in a medley of the corresponding passages applied equally to both modes: "Those who say that God can be derived by understanding from an as. sumed starting-point, rendering one truth 'derivative' of another...do not mean that God himself is something 'derivative'...they mean that it is we who proceed to God, whose existence we do not yet understand, from other truths of nature which we do (or we perhaps at least understand both better when the argument is over)." When the different senses of derivation are untangled, this line seems no more or less sensible for arguments of 'understanding' than arguments of 'reason'. Hegel has not clearly delineated the two, and at any rate his critique of the first, even if meaningfully circumscribed, pivots on an equivocation which his own example further documents.

Hegel's modes do not seem capable of supporting any plausible contention about the demonstrability of God's existence vis-à-vis traditional theology. What we've seen emerging here is, rather, a much more innocuous kind of claim about how valid or sound proofs for God's existence, every bit as cogent on one mode as the other, are merely to be regarded, or the proper attitude that one is to entertain when regarding them. Something like this is what seems to come across when Hegel's comments on proving God are placed in the broader context of the Logic as material tangential to the theme of this work. While Hegel's acceptance of 'reason' appears to add little clarification to his rejection of 'understanding', it might seem clear enough that Hegel's remarks bear some resemblance to a motif of his logic in the idea that conclusions of (theological) arguments must possess explanatory power for retroactively displaying ("exhibiting"/ aufzeigen) the derivative nature of the premises from which they have themselves derived. Hegel's system of thought is popularly considered to have a certain affinity to the idea that human experience be comprehended in a stage-wise or "dialectical" process by which a conflict among inadequate or partial conceptions is resolved into a more complete and holistic one. The suggestion, alluded to earlier, is that the true significance of Hegel's comments on theology be construed, and vindicated, as conforming to this pattern. That Hegel's above point may be so inspired by a general disposition to how truths of the world are apprehended is perhaps more clearly brought out in what he says for conceptions of 'reason' than against those of 'under- 
standing'. Under the 'mode of reason' the conclusion that God exists is regarded not merely as a logical product of antecedent conceptions or a deductive starting-point, but as "absorbing" the premises in itself and upholding their truth in a more enlightened perspective of the whole. One gets perhaps a kind of bootstrap phenomenon with the proofs of God viewed less as a linear progression through so many mechanical steps (some empirical data, a principle of reason or two, and a deductive presto, Q.E.D.) to a desired end, than a reciprocal exercise which, once started, establishes a relationship illuminating both ends. The distinction here is not really how to prove God's existence, but what it means to do so, and the whole point about pitting 'reason' against 'understanding' is that one represents a way of looking at the proofs more congenial to the Hegelian paradigm, whereas the other, consisting of a logically independent starting-point and (merely) a deductive consequent, does not enter into this "spirit." The question is no longer that of two different kinds of arguments in the history of theology to search for historical examples of-a question of arguments as they are, or as they should be, and where those of one kind presumably succeed while those of the other do notrather, it is a question of two kinds of characterization for what the process itself of theological proofs is and has always been.

J. N. Findlay suggests a view along this line for some of Hegel's comments in $\$ 50$. According to Findlay in his foreword to the Wallace translation, the thesis that Hegel wishes to establish is not that (any of) the traditional proofs do not prove anything, but that "the socalled proofs of the Divine Existence are not what they are ordinarily thought to be." "The point which Findlay gleans from this is, viz., that they are not "purely affirmative reasonings in which," after Hegel's own wording above, "what we start from furnishes a fixed, solid basis from which we pass on to something which has the same solidity as its premises." Findlay quotes Hegel's observation on "the exaltation of the mind from the world to God" charging that "the metaphysical proofs of a God are defective interpretations of the process" (mangelhafte Auslegungen und Beschreibungen); Hegel indicates that the defect of the demonstrative process of exalting minds to God does not "express" merely "with sufficient prominence" the "real being" or "absolute truth" of God. This is different from saying

8 HL p. xii. 
that the process-i.e., in the previous (\$36) phraseology, by which "we (or the mind) proceed (s)" to God-does not work, that the theistic proofs cannot be said to prove the conclusion that God exists, i.e., or "express" this proposition at all. While presumably no logical process of earthly minds will ever "sufficiently" or "prominently" enough be able to deliver "absolute truth" or "real being" from contingent facts of appearance, Hegel evidently concedes that the traditional proofs, even given his criticism, do succeed in expressing their result. ${ }^{9}$

Findlay sees the criticism on the lesser count of "insufficient prominence" as a corollary to Hegel's dialectic; here on the proofs of God, but for Hegel generally:

The action of thought is to negate the basis from which it starts, to show it up as not being self-subsistent, and so to have in it a springboard from which it can ascend to what is truly selfsubsistent and self-explanatory.

Hegel's entire treatment of the "process" of theological argumentation in $\$ 50$ is seen as a replication of the dialectical process:

In this passage Hegel not only explains the argument for selfexplanatory, absolute being, he also explains the whole nature of the dialectic. Nowhere does it merely elicit what some firm basis entails: everywhere does it rather overturn its basis as involving incompleteness or conflict, and then progresses by a leap to something more harmonious and complete.

Thus, the critique of 'understanding' from which, incorrectly on this interpretation, the argument of (1)-(3) was constructed, would for Findlay be a statement of the correct dialectical outlook on what, generally, the nature of theological argumentation is:

Those who expect all thought-advance to be that of the deduction of conclusions from firmly established premisses are quite in-

\footnotetext{
${ }^{9} \mathrm{HL}$ pp. 81f; corresponding passage, WL p. 132. Hegel's charge that the qualified with the disclaimer, oder vielmehr nicht herausheben, i.e., or much more, or more accurately, do not render prominent, emphasize, etc., the appropriate nature of the thing they express. The Wallace translation combines the overstatement and the relation which in the original makes this point itself more prominent.
} 
capable of dialectical thinking: in dialectic it is the insufficiency of the premisses that leads to the more sufficient conclusion. ${ }^{10}$

There are arguments, of course, whose premises are "insufficient," not merely in the metaphorical rhetoric of 'firmness' or 'stability', but because they are false, or do not deductively entail the alleged consequent, so that in either case the conclusion of the argument is not "expressed" by the premises. This, however, is not Hegel's criticism of the arguments for the existence of God.

In lieu of a survey of "the whole nature of the dialectic," which admittedly may shed textual insight on at least the biographical question of Hegel's intentions, there is still a problem for the Findlay interpretation as to what the net significance of Hegel's commentary in this and the preceding discussion comes to. If Hegel's objection throughout all of this is that the traditional demonstrations of rational theology are simply "not what they are ordinarily thought to be," there is still the problem of identifying what in fact they were in the history of rational theology ordinarily thought to be, and specifically, who thought them to be like that. Hegel does not seem to be proposing anything new or out of the ordinary about the relation between God and the world, or the contingent facts constituting the world and sometimes packed into theological arguments. It seems quite common among theologians to think of God as self-subsistent, wrapped up and absorbed, and so on. The suggestion merely that one conceive of God, or the conclusion that God exists, in the prescribed way, certainly does not seem to implement the earlier distinction between 'teleological' and (other) 'cosmological' forms, or any point about how those who propound them regard the role of contingent premises-as illustrated, for instance, in the case of Aquinas, who argued both forms. God is quite ordinarily conceived as the necessary or self-explanatory being, and facts of the world, including those invoked in the standard theistic arguments, as contingent, requiring a necessary "basis," unexplained and requiring explanations, etc., which it is precisely the essential function of the traditional arguments to provide. What does Hegel's dialectic add to this? There still seems to be a problem of locating any historical target that Hegel's insight is supposed to be shooting at here, even on Findlay's more sporty characterization.

10 HL pp. xiif. 
The dialectical significance of 'reason' has not made it obvious that rational theology suffers an improper reliance upon 'understanding'; nor does it ensure that Hegel's polemic against the latter is free of the confusion noted in $\$ 36$. The "mistake" which Hegel debits to the account of those working in the tradition of rational theology, who have formulated the arguments of this tradition and have done the "ordinary" thinking about them, appears not to pertain to the manner in which they ordinarily thought of their arguments-since there is no evidence of their having so mistaken any such ontological status of their premises as "dependent," "derivative," "explained" by, etc., the nature of God-but again only conceivably to the mere fact that they were presenting logically deductive "one-truth-on-another" argumentation at all. But Hegel, as we've seen, clearly cannot have this criticism, since it rests on equivocation. If, as Hegel's own criticism of the 'understanding' seems to do, anyone arguing for the existence of God really were "mistaking" the derivation going from the world to God in a logical demonstration, with the "exaltation of the mind" (Hegel's expression Erhebung here being variously translated in Wallace as "exaltation" and "upward spring") as involving an ontological dependence of God on the world, then perhaps the appropriate thing to say about this would be that such a person simply did not have in mind the right object of the argument in the first place, that the argument is demonstrating something other than the traditional concept of God. But it would be very bizarre if Hegel's criticism that rational theology has historically been laboring under the too myopic view of 'understanding' hereby reduced to calling all of the Church Fathers atheists, and if this is the objection, it could surely have been more incisively put.

It is difficult to gather from this general contemplation of God and the world any very helpful instruction that Hegel's dialectic has for reconceiving the traditional arguments of theology. This is apparent upon consideration of the arguments and the traditional conception of them, but more so as one looks closer at the dialectic and Hegel's conception of it. Surely the issue at stake for Hegel is not whether "all thought-advance [is] to be that of the deduction of conclusions from firmly established premises" but whether, no "thoughtadvance" can be made this way, whether all thought-advance has to be made some other way. This seems to be Hegel's alternative and the view underlying Findlay's above suggestion linking Hegel's other 
way, the dialectical method, with the proofs of God. By Hegel's method, the discovery of truth evolves in a triadic succession of "moments" in thought, synthesizing a comprehensive moment of "harmony" out of an ostensible contradiction of "incomplete" moments. But this does not seem to be what's going on in the theistic arguments, either on Hegel's view or on Findlay's reconstrual of it. It is not being asserted, after all, that the premises of theistic arguments really do "conflict" with or (even ostensibly) contradict each other. In what following the premise-stage is really the only other stage to a theistic argument, the conclusion that God exists-presumably an important existential fact (other qualities of God's existence aside for the "moment") toward (at least a more) "complete" picture of the world-again is not "harmonizing" antithetical elements in doing so. It seems to stretch the point to say that the conclusion here, as Findlay puts it, is "negating" or "overturning" premises: The resolution or harmonizing of conflict takes place only if there is conflict or discord to be resolved or harmonized, and one presumably does not "overturn" something which is merely "incomplete"-one simply completes it. This kind of harsher 'negating/overturning' characterization seems to outdo the idea of theologians diving off "springboards" of logic." With the exaggeration of 'incompleteness' into the notion of 'conflict', or when the starting-point is this radically "insufficient," i.e., to the extent that the premises are self-contradictory rather than merely not "self-subsistent," Hegel's "leap of reason" here begins to look more like Kierkegaard's "leap of faith" than anything that could be associated with Aquinas' logical deductions.

It is unclear what it is about the premise-conclusion structure of the deductive proofs of God for which Hegel means his dialectical model to provide a less "defective description." One might think perhaps that a part of rational theology at least remotely suggestive of this more extreme analogizing to Hegelian dialectic would be causal regress argumentation. As accentuated in perhaps the most generous view with a formulation in reductio ad absurdum format, the prospect of tracing back an infinite series of causes may appear to give rise to a contradiction or to 'conflict' with the existence of catsation in the world: Thus, it may be felt that an explanatory regress cannot stop without leaving the last examined cause itself uncaused, or again, that

11 Hegel too indulges in some poetic eloquence here, complementing the notion of Erhebung with the term Sprung, WL p. 131. 
it cannot go on forever, either, without leaving even the cause one started with, or the infinite series itself, ultimately unexplained. This predicament, then, might seem to provide ideal bait for a resolution or "harmonization" in the dialectical model as the mind is "exalted," etc., to a higher necessary cause. Unfortunately, Hegel himself, we've seen, does not seem to take such cosmological argumentation as exemplary. Though of course any logical proof can be given reductio style, Hegel's own example of the teleological argument would seem to lend itself more reluctantly to even this intuitive sense of paradox or conflict in its premises. It certainly does not embody this idea more perspicuously than other contingent argumentation, which if it is tempting to think should be refiled as argumentation that Hegel also approves, would again seem to deplete the supply of arguments that he is supposed to disapprove.

While it is questionable in what descriptive aspect the dialectic could apply to theology and whether Findlay captures an intelligible sense of even Hegel's intention generally, it appears especially problematic here that Findlay's suggestion could clarify what Hegel intends in $\$ 36$. It is not on this paradoxical nature of the premises that Hegel's highlighting of the teleological example in that passage seemed to focus. The focus of the example in $\$ 36$ is, rather, the "wrapped up" and "absorbed" character of the conclusion, which need not involve, nor does Hegel indicate it involves, the idea of conflict and negation that concerns Findlay in $\S 50$. Though this observation about self-subsistence, and so on, in conclusions, again charitably entertained at some distance, may recommend itself in a very general way to some skeletal aspect of Hegel's model when the conclusion happens to be God, still the "dialectical" concept seems to drop out. It seems difficult here to pursue the Findlay route with any deeper connection to Hegel's phases of 'understanding' and negative and positive 'reason' lurking around in Findlay's reference to $\$ 50$ and elaborated by Hegel in \$\$79-82. Even if one could read Hegel's three stages into the traditional theological demonstrations with neat little verständige, negativ-vernünftige, and positiv-vernünftige components running through them, this does not square with the $\$ 36$ criticism where some portions of rational theology, or entire (cosmological) premise-conclusion proofs, were being characterized as stuck somehow in an "understanding" stage. While that earlier criticism did not seem convincing, it is similarly not clear here how Hegel or Findlay distinguish 
regarding the premises alone of a deductive proof as representing a stage of 'understanding', from thinking in the correct dialectical mode about them. As has been noted, it can surely be presumed that the historical inventors of the arguments were aware of the contingent, dependent, transitory, apparent, etc., nature of the world, and facts about it, in their premises, while they should have been equally aware-and the Hegelian dialectic, nevertheless, does not enhance the aptitude of the finite mind to be more "sufficiently" aware-of the necessity, self-subsistence, eternal being (in the Findlay citation: "beyond and above that appearance," the "real being" and "absolute truth" of the universe), etc., of the nature of God in the conclusion. If this is supposed to be what it means to view the premises as "fixed" and "solid" (das Festes), then the only thing in the history of philosophy that would seem to satisfy Hegel's criterion of viewing them as provisional "springboards" would be, not any possible version of, or version of thinking of, the traditional theological arguments themselves, but rather something very much like their use in the infamous Cartesian circle.

Despite the difficulty in how Hegel's 'reason'/'understanding' distinction cuts across the historical enterprise of proving God and provides a basis for criticizing (or applauding) any of the contingent arguments, the tenor of Hegel's foregoing discussion may allow one to anticipate Hegel's favorable disposition to theistic argumentation which does not rely upon contingent premises. If insisting that contingency in logical demonstrations somehow compromises the necessary being of God, Hegel endorses the style of proof undertaken in the ontological argument. This approach is intimated in Hegel's remarks on the nature of God and of dialectical conclusions in that it does not go from the world to God at all, but rather proceeds from the concept of God, to God, by "unwrapping" the ("self-subsistent" and "absorbed") content of that concept. However, as before in the criticism of contingent proofs, there is nothing in Hegel's endorsement of the ontological proof that appears to profit in any distinctive way from the dialectic. Hegel has not gotten much mileage out of the dialectic for any novel insight into the concept of God, and it is awkward trying to go any further here with the nomenclature of 'negating' and 'overturning'. It is an interesting contrast to the preceding case, and other arguments of 'reason', that not even Hegel tries to explicate this process of the mind to God on the dialectical model. In the case 
of the ontological argument it is certainly still less plausible that the existence of God in the conclusion could be reconciling any insufficiency, contingent or otherwise, inherent to the premises, since the "starting-point" of this argument already is God. Certainly no part of this starting-point is being negated or overturned by anything else in the argument, nor is there any leap to something more "harmonious and complete" encompassing or explaining the starting-point-just the opposite: The conclusion is no more "sufficient," or even meaningful, than the initial concept (which is exactly how some have attacked the argument), and the scope of the conclusion is actually more restricted than the premise, picking out and concentrating upon only one attribute (existence) presumably already present in the starting concept (the ontological argument could in theory be used to generate other less controversial attributes). Whatever its amenability to the dialectic, Hegel cannot, of course, claim the patent on this technique of argument, and Hegel's approval does not avail itself of any essentially revamped version (Auslegung or Beschreibung) of the argument, but rather is confined solely to refuting Kant's refutation of it.

In $\S 51$ of the Logic, Hegel says this about Kant's celebrated refutation of the ontological argument:

The uniformly favourable reception and acceptance which attended Kant's criticism of the Ontological proof was undoubtedly due to the illustration which he made use of. To explain the difference between thought and being, he took the instance of a hundred [British] sovereigns [the kind you put in a "man's purse" (Taler)], which, for anything it matters to the notion, are the same hundred whether they are real or only possible, though the difference of the two cases is very perceptible in their effect on a man's purse.

Continuing, Hegel assents - in fact "nothing can be more obvious" (einleuchtend) - to the principle that "anything we only think or conceive is not on that account actual," but finds its development in Kant's illustration objectionable (in Hegel's more cautious phrasing, a "barbarism of language"; more literally, Hegel's locution, eine Barbarei, doesn't narrow it down to language). Hegel objects apparently to the presupposition of the analogy, that we have "notions" (Begriffe) of things like a hundred sovereigns. This objection, however, receives only a secondary billing in the original, where it is relegated to the 
prefatory clause of another statement reiterating in more detailed philosophical guise the obvious thought/actuality principle (the translation, enacted with the routine hatchet editing on sentence structure, obscures somewhat the intended relation and importance of these observations):

And [misleading, since this point has already been made], putting that mistake [the 'notion' problem] aside, those who perpetually urge against the philosophic Idea the difference between Being and Thought might have admitted that philosophers were not wholly ignorant of the fact. Can there be any proposition more trite than this?

Thus, arriving at what seems to be his primary objection, Hegel observes:

But after all, it is well to remember, when we speak of God, that we have an object of another kind than any hundred sovereigns, and unlike any one particular notion, representation, or however else it may be styled. It is in fact this and this alone which marks everything finite: its being in time and space is discrepant from its notion. God, on the contrary, expressly has to be what can only be 'thought as existing'; his notion involves being. It is this unity of the notion and being that constitutes the notion of God. ${ }^{12}$

In the long version of the Science of Logic published before the Encyclopedia, Hegel's response does expend at least a few remarks to give some additional philosophical articulation, as part of his discussion of 'Being' generally, to the preliminary point (Kant's Barbarei) shoved aside in the later work:

But this so-called concept of the hundred dollars [A.V. Miller, also an Englishman, deciding to do it phonetically] is a spurious concept; the form of the simple self-relation does not belong to such a limited, finite content itself; it is a borrowed form attached to it by the subjective understanding; the being of the hundred dollars is not self-related but alterable and perishable.

${ }^{12}$ HL pp. 84f; WL pp. $135 f$. 
Here too, while accusing Kant of a "confused clumsiness" (verworrene Schwerfälligkeit) in the distinction between the 'concept' (for Hegel "figurate conception" (die Vorstellung)) of, say, a hundred dollars on the one hand, and "the state of my fortune" on the other, Hegel impugns the attractiveness of Kant's argument as being induced by the simplistic illustration:

The main thesis of the Kantian criticism was that existence or being (these being taken here as synonymous) is not a property or real predicate, that is to say, is not a concept of something which could be added to the concept of a thing... . This criticism, through its popular example, has made itself universally plausible: who does not know that a hundred actual dollars are different from a hundred merely possible ones? that they make a difference to the state of my fortune? Because this difference is so obvious with the hundred dollars, therefore the concept, that is, the specific nature of the content as an empty possibility, and being, are different from each other; therefore the Notion of God too is different from his being, and just as little as I can extract from the possibility of the hundred dollars their actuality, just as little can I extract from the Notion of God his existence; but the ontological proof is supposed to consist of this extraction of the existence of God from his Notion.

And so again Hegel's reply:

Now though it is of course true that Notion is different from being, there is a still greater difference between God and the hundred dollars and other finite things. It is the definition of finite things that in them the Notion is different from being, that Notion and reality, soul and body, are separable and hence that they are perishable and mortal; the abstract definition of God, on the other hand, is precisely that his Notion and his being are unseparated and inseparable. The genuine criticism of the categories and of reason is just this: to make intellect aware of this difference and to prevent it from applying to God the determinations and relationships of the finite. (Miller's italics, following Hegel's throughout.) ${ }^{13}$

${ }^{13}$ Hegel's Science of Logic, trans. A. V. Miller (London: George Allen \& Unwin LTD, 1969), pp. 86-90. Wissenschaft der Logik (Surkamp, Vol. 5), pp. 88-92. 
As an argument aimed to knock down Kant's objection to the ontological argument, this commentary does not seem very impressive, or regardless of whether Kant's objection may indeed be mistaken, to show with much plausibility what is mistaken about it. Hegel, we see, finds the distinction between thought and being "obvious" (and "trite"-Hegel's own word, "trivial," losing out to the translator's quest for adventure) and apparently considers it naive of Kant to have made this point or to have based his objection on it. Actually, if there is any naivete going on here, it seems much more obviously to be Hegel's assumption, and the argument which he then bases his argument on, that this really is Kant's point against the ontological argument. When the distinction between thought and being is merely, as Hegel quite aptly acknowledges, the fairly unexciting idea that thinking things does not make them so, this distinction can surely have very little to do with what is Kant's objection, viz., that existence is not a predicate. Of course, imagining lots of things about objects of thought other than their being (in existence) does not make it so either, i.e., as is also very obvious when objects do indeed have being and are seen, moreover, to be otherwise: even though these other things may be perfectly legitimate predicates. The idea that "anything we only think or conceive is not on that account actual"this idea pertaining to the existence of objects, but subsuming any genuine predicates as well-sweeps too broadly to accomodate Kant's point about what is or is not a predicate. What Kant presumably wants to show is (i) that asserting the existence of an object is, qualitatively in some way, different in kind from asserting other things about it, and (ii) that this difference renders the former not a "predicate." Thus, as perhaps better indicating the sense of this contention, it would be meaningful to ask whether a hundred dollars one may have in mind exists in one's purse as well, while it would not be meaningful, for the case of nonexistence, to ask whether the concept of a hundred dollars one is entertaining should really be ninety-nine or one hundred and one. It would not be a too arduous feat to show that existence is at any rate a rather weird predicate, but whether Kant is right or not, there is certainly nothing "trite" or "trivial" about this position, and in fact it has, of course, been heartily disputed. ${ }^{14}$

14 In G. E. Moore's epic essay, "Is Existence a Predicate?" presented with a rejoinder in Alvin Plantinga, ed., The Ontological Argument (Garden City, New York: Doubleday \& Co., Inc., 1965), pp. 71-110. 
It is unlikely, then, that Kant's illustration of the hundred dollars, if as Hegel claims its only purpose is to draw the general distinction between thought and being, could really be, as Hegel also claims, what makes or ever did make Kant's objection to the ontological argument seem persuasive. The purpose of Kant's illustration is not, after all, this general distinction, but rather, as a close reading even of Hegel's own remarks in the earlier Science of Logic (omitted in the Encyclopedia) indicates, is and in fact contrary to Hegel's claim seems fairly well understood to be, that the content of a concept is not itself enlarged through instantiation out in the world; existence is not one of the "predicates" which go into constituting or determining what a given concept is a concept of. Thus, one does not alter the concept of a hundred dollars by saying that a hundred dollars exists in any given person's purse. But now this-specifying a general relation between concepts, their nature and determination on the one hand, and existence or their instantiation on the other-is very different from asserting merely that thinking things so does not make them so, a claim that would be true whether existence were a "predicate" or not. If existence were a predicate for building concepts, then since fantasizing still of course does not change the world, this would simply generate the idea of concepts that are incorrectly built. Along with the possibility of self-contradictory concepts, concepts whose "predicate" elements conflict amongst themselves, one would have the additional possibility of conflict with the real world of being. Hegel himself already authorizes the idea of "false" or "spurious" concepts on the different considerations (involving "self-relation," etc.) when he criticizes Kant's alleged concept of a hundred dollars: viz., as not really being one, as being, rather, improperly put together (Hegel's own locution, falscher Begriff, literally "false concept"). The point is that there is at least nothing absurd in this view, as there presumably is in the general view that thinking propositions makes them true; nor, again then, should Kant's position on the former, denying that existence is a predicate, seem at all trivial, since with this view the ontological argument, for anything that has been said here, really is out of business. Existence is excluded as any internal part of concepts that can ever have determinant bearing on content; thus, just as the concept of a hundred dollars is not itself in any way augmented by the external circumstance that it is, or is thought to be, existentially instantiated, so the concept of God, as the being than which none 
greater can be conceived, does not raise the question of whether that content is something which could ever be greater or lesser as a function of whether it is thought to be realized in the world-any variant of the ontological argument which in this way "predicates" existence as a determinator of conceptual content fails with a false premise. ${ }^{15}$ This "so" is not very well represented in Hegel's "therefore" above. While Hegel does appropriately characterize the consequent as a view about the nature of concepts, the rendering of the illustration in the antecedent should also be, the simply more general form of, the same kind of view; whereas Hegel seems to picture Kant as trying to squeeze the desired result out of the difference merely between having a hundred dollars and not having a hundred dollars. This is not what Kant had in mind, and it is very doubtful that this has been a rampant inference in the minds of Kant's readers either.

This seems to take care of Hegel's main point about the eccentricity of the concept of God. It does not matter whether the substantive point in Kant's illustration is trite or trivial, but only whether, properly understood, it's true. If one obliges Hegel's suggestion to set aside the incidental obstacle that a hundred dollars is not a conceptpresumably the conceptual-determination/existential-instantiation distinction could as easily be made with a concept of some other finite entity to Hegel's liking and passing his test of self-relation-Hegel's argument amounts to the claim that it is not, i.e., as applied to the distinctive concept of an infinite God. This does not seem a very profound reply to Kant. Surely it settles very little to say merely that Kant's illustration, with a non-"spurious" concept plugged in, then, works very well for finite concepts, while it is the "abstract definition" of the concept of God that existence be a predicate only in this one

\footnotetext{
15 There need be no quarrel here with any view about the computation of 'greatness': The ontological argument does not, as does one of Descartes' arguments postulating God as the necessary cause of an idea, have any immediate interest in evaluating the greatness of concepts, nor does Kant's point hinge in any way on the greatness of existence: Existence may well be the nobler part of being, i.e., it may be greater in some sense to exist than not to exist, but this proposition is simply irrelevant for the ontological argument if existence is not a predicate of concepts. (Some existent objects may concur in this proposition, or in how much worse it would be to cease existing, etc.; or again, one might even concede that a concept is somehow, though not in virtue of its predicate constituents, a greater concept whenever it is a fact that its object exists, or when the concept is actually conceived, and so on.) One would still not be conceiving a greater being simply by thinking that it exists, or violating the concept formula for God by thinking he doesn't.
} 
special case. If Kant's view that existence is not a predicate is correct, then the special case would simply be another "false concept" in violation of this general rule of concept-building in the familiar case, and the bare assertion that there is one exception to the rule is nothing but a point-blank repetition of the ontological argument. Certainly, in general, it does not constitute a very awesome defense to concede that one's view is successfully falsified as a rule in all other cases, but is therefore to be declared simply an exception. To simulate the same rough treatment given Kant here in a point that might as forcefully be turned around on Hegel: Surely one defending the ontological argument cannot assume that the philosophers criticizing the argument are so ignorant as not to have recognized the privileged status claimed for the concept of God, and that this is indeed what the ontological argument is all about. While Hegel seems to saddle Kant's criticism with some trivial exploitation of a practical difference between having an actual God and a merely possible God, it is of course the whole strategy of the ontological argument that there is a conceptual difference between this case and all others which, for it, makes mere possibility impossible. No propounder of the ontological argument ever suggested that the case of God was not unique or that the argument could be applied to finite objects, and so it is difficult to see how Hegel's response--essentially that the concept of God is in this crucial respect to the argument different from all other finite onesconstitutes much of an advance here.

At most what could perhaps emerge from this is not a new way to refute Kant, but merely another way to refute Gaunilo: At the time Saint Anselm premiered the ontological argument, monk Gaunilo's reductio ad absurdum objection against it, that if the argument went through for God then one would be licensed under the same logic to think lots of other things into existence as well, was quashed by Anselm on grounds that this move for other ("greatest possible") objects (including finite ones) was, in effect, not conceivable, as there were no other real concepts for the argument to operate on. In contrast, the residual implication of Hegel's commentary would be to redirect Kant's criticism, now against Gaunilo instead of Anselm, so as to provide yet another reason why objects other than God will not be able to claim existence in their concepts, viz., since for them existence is not a predicate that could belong to any concept of a thing, even if such concepts were possible. This would surely have to seem less con- 
vincing to Gaunilo than what Anselm originally told him, for the simple reason that the answer, i.e., as it should seem unconvincing to Kant as well, sounds like such an ad hoc abutment of the question. Again, surely anyone disposed to criticizing the ontological argument in the first place has noted, if nothing else, that God is indeed supposed to be infinite, and here in this instance a concept is indeed supposed to contain existence as a predicate and to be therein essentially different from all other concepts. Hegel, we see, once the main thrust of his response is sifted out from the confusion and historical mistreatment that characterize his discussion on this topic, does little more than agree.

Stephen W. BALL

The University of Michigan 